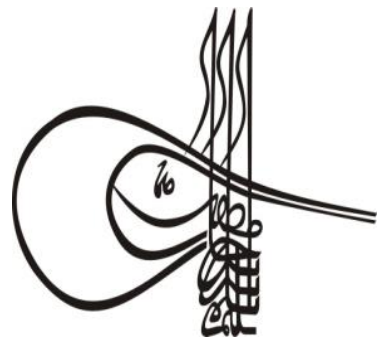

Received/Geliş: 10.03 .2019
Turkish Studies

Volume 14 Issue 3, 2019, p. 1697-1711

DOI: 10.29228/TurkishStudies. 22864

ISSN: 1308-2140

Skopje/MACEDONIA-Ankara/TURKEY

Research Article / Araştırma Makalesi

Article Info/Makale Bilgisi

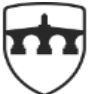

INTERNATIONAL BALKAN UNIVERSITY

EXCELLENCE FOR THE FUTURE IBU.EDU.MK

$\checkmark$ Accepted/Kabul: 10.06 .2019

Go Report Dates/Rapor Tarihleri: Referee 1 (25.03.2019)- Referee 2 (14.04.2019)- Referee 3 (23.04.2019)

This article was checked by iThenticate.

\title{
ARDEŞEN YÖRESİ HALK MÜZİĞİNDE DESTAN TÜRÜ
}

\author{
Erkan SARAL* - Burçin UÇANER ÇİFDALÖZ
}

\begin{abstract}
ÖZ
$\mathrm{Bu}$ çalışma, Doğu Karadeniz Bölgesindeki geleneksel müzik pratiklerinin araştırılması kapsamında, Rize iline bağlı bulunan Ardeşen ilçesindeki yöre halkının geleneksel müzik kültürü içerisinde destan türünün incelenmesi maksadıyla yapılmıștır. Bu bağlamda konu ile ilgili olarak yöredeki kaynak kişilerle alanda görüșme yapılmıştır. Yapılan görüşmeler sonucunda alınan ses kayıtlarının transkripsiyonu hedeflenmiştir. Çalışmada nitel araştırma yöntemlerinden biri olan alan araştırması yöntemi kullanılmıştır. Alan çalışması öncesinde ilgili edebiyat taranmış ve sonrasında alanda belirlenen kaynak kişilerden plansız görüşme yolu ile derlemeler yapılmıştır. Yapılan derlemeler, Mixcraft Müzik ve Ses Ayrıștırıcısı program kullanılarak notaya aktarılacak veri konumuna getirilmiş ve Mus 2 adlı nota yazım programı yardımı ile notaya alınmıștır. Yapılan derlemeler sonucunda yörede yaşayan insanların müzik pratikleri arasında bulunan destanların edebi ve müzikal analizleri yapılmıştır. Çalışmada derlenen destan dörtlükleri aynen aktarılmıştır. Buna göre destanlarda on birli hece ölçüsünün kullanıldığ1 belirlenmiştir. Ritmik açıdan her ne kadar dört zamanlı ölçüye uyum sağlasa da destanların, genellikle serbest zamanlı olarak icra edildiği görülmüştür. Destanlarda konu içeriği olarak; hasret, ayrılık, gurbet, aşk ve ölüye ağıt isslenmektedir. Çoğu zaman yöre halkı bu geleneksel müzik türünü doğaçlama olarak da seslendirmektedirler. Destanlarda geleneksel olarak kullanılan bir ezgi kalıbı bulunmakta ve yöre halkı bu kalıba "destan kaidesi" ismi vermektedir. Destanlar Ardeşen yöresinde tulum ya da kemençe çalgısı eşliğinde okunabildiği gibi, yalnızca vokal olarak da seslendirilebilmektedir.
\end{abstract}

Anahtar Kelimeler: Halk müziği, Destan, Ardeşen.

YL Öğrencisi, Ankara Hacı Bayram Veli Üniversitesi, E-posta: saralerkan.53@gmail.com

\footnotetext{
** ID

Doç. Dr., Ankara Hacı Bayram Veli Üniversitesi Türk Müziği Devlet Konservatuvarı Müzikoloji Bölümü, E-posta:
} ucanerts@mynet.com 


\title{
EPIC TYPES IN FOLK MUSIC OF ARDEŞEN REGION
}

\begin{abstract}
This study was conducted in order to investigate the epic genre in the traditional music culture of the local people in the Ardessen district of Rize province for the pupose of the traditional music practices in the Eastern Black Sea Region. In this context, the people in the region were interviewed in the field about the subject. As a result of the interviews, the transcription of the audio recordings was targeted. In the study, field research method which is one of the qualitative research methods was used. Prior to the field study, the related literature was scanned and then compilations were compiled through unplanned interviews from the source persons determined in the field. The compilations were brought into the data position to be transferred to the note by using the Mixcraft Music and Audio Parser program, and were noted with the help of the writing program called Mus 2. As a result of the compilations, literary and musical analyzes of the epics among the music practices of the people living in the region were made. In the study, the epic quatrains compiled were transferred exactly. According to this, it was determined that eleven syllable measurements were used in epics. Although the rhythmic aspect was adapted to the four-stroke scale, it was seen that the epics were generally performed in free time. As the subject content in the epics; longing, separation, expatriation, love and dead lament are being processed. Most of the time, the local people perform this traditional type of music as improvisation. There is a melody pattern that is used traditionally in the epics and the people of the region give this mold the name of "epic base". The epics can be read in the Ardessen region by accompaniment with tulum or kemençe and can only be performed as vocal.
\end{abstract}

\section{STRUCTURED ABSTRACT}

This study was carried out using qualitative research method because it is mainly based on participant observation and experience. It is called the field research model. Nowadays, field research is not only about observations in rural areas, participant observations and interviews. Widespread use of technology and communication network, the emergence of ways to access information over the internet support field research in virtual environments. It is thought that the traditional music culture in the Eastern Black Sea region varies according to the regions and this difference should be evaluated within the scope of the Ardesen region. It is foreseen that different musical forms will be found when the forms of living in the region are examined. Also; studies that are considered to be necessary in the field of musicology; it needs to be qualified by locating, revealing and archiving folk music data. This folk music data should be the data collected in a structured form by the techniques of compiling and transmitting the manner in which it is spoken. The source person determinations made in the region were selected among the people who can transfer the style of traditional working and utterance. During this election, the leaders of the region 
were consulted, and information was received from people who work professionally in traditional music circles.

The general purpose of the study is to contribute to the national and international promotion of the music values in our country. In this context, our specific purpose is to reach the sound recordings about the epic genre in the music culture of Ardessen region, to archive the sound recordings obtained as a result of the compilation studies and to make various analyzes. Although there are some studies on the music culture of some regions of the Eastern Black Sea Region, it is thought that these studies do not express the music culture of the region fully. From this perspective, music culture in the eastern part of the region; both in terms of melodic and rhythmic structure and the type of language and instrument show a different structure. This study shows a different importance in terms of revealing this difference. The data reduction process was provided by determining which data should be used in the study. The intent here is the elimination of sound recordings close to each other. After that, visualization of the data was done. This means that audio recordings should be recorded and converted to picture format. At this stage, an attitude towards understanding the whole process has been demonstrated and the result has been reached.

There is no specific pronunciation of the epic type in the traditional music culture of the Ardeşen district. It entered the district's dialect as a "destani". As a Word meaning it includes the meaning of the story, tale and fame. In many regions, covering the subjects such as heroism, bravery, death and disaster, it takes place as the the general name of the narrative tradition written in a prose and verse. According to the research conducted by us in the district of Ardessen, traditional epic genre; unlike the explanation of the emotions, the narrative part of epic takes place entirely together with musical performances. In Ardessen district, the subjects of traditional epic genre include love, illness, separation, death, expatriation, immigration, disaster, shortage of livelihood but love and death come first among the most common issues. In the historical process, the epic writers who grew up in Ardeşen district are mentioned. Those epic writers are also characterized as a folk lover / bard. Those epic writers who aren't suspicious about their performance in performing arts have taken part in certain executive environments that have been adopted by the local people. The epic writers, while performing their arts, not only tell the results of their own events but also convey emotions of other people in their words. Although it is not very detailed like the minstrelsy tradition, it is also possible to mention a master - apprentice relationship here. According to the information gathered from the source people interviewed in the district, some epics were written, others could not be written. It is seen that if the poems written in terms of form should be examined in terms of poetry, folk poetry is written in the verse unit and eleven syllable measurements were used. The syllable stops may vary depending on the tune pattern used. The rhyme pattern in the epic type is a a a b. The number of stanzas can vary and can reach up to forty quartets. The melody pattern of many epics compiled in the region is the same. However, in some villages, it can be seen that there is a change in the reading style by adhering to the mold.

As known from the researches of ethnomusicology, verbal melodies in traditional folk music take shape in relation to the sound fields of the 
instruments used in the region. The sound field used in the epics was formed according to the sound fields of the "tulum" and "kemençe" instruments used in the region. Due to the limited sound field of the "tulum", which is the most commonly used instrument in the Ardessen district, only the voices of "hüseyni" and "uşşak" are used in some epics. However, some sources Show that we have obtained from people; epics, played with "kemençe" such as "hicaz" and "saba", can be in addition to the voices of "hüseyni". Many epics are said with a single tune pattern. In this study, this tune pattern can be said as "characteristic epic base.

There is a characteristic melody pattern in the epics collected in the region. This melody pattern may vary slightly from village to village in terms of style and attitude. Compiled epic quatrains were written with eleven syllable dimensions. In almost all quarters, a long-term reading of the tenth syllable of the second and fourth lines was encountered. This situation is also expressed as musical. In the personal interviews, it was seen that the quatrains of the epic were mostly read by a characteristic melody. In addition, two different sounds were encountered in the study. These melodies are thought to be personal productions. The number of continents can change in epics. Only one quartet of epics can be as well as the number of epics numbers of which are reaching fortunes were determined by us in the negotiations. The corresponding source mentions the existence of these epics, but also states that there is not a whole fortyfour epic in his mind.

As a result; it has been seen that the epics have a traditional melody pattern and this melody pattern can be interpreted by different readers with slight changes. In this study, the seven epic texts mentioned with this melody pattern are mentioned. In addition, different epic bases (very rare) were found. Although the rhythmic structures are compatible with all four dimensions, many epics are performed with free rhythm. According to the Arel system, the epic melodies mentioned in the study was dertected to correspond to the Uşşak, Hüseyni and Kürdi authorities in Turkish music theory. However, local people refer to these tunes as a pedestal, and should not refer to a nomenclature that distinguishes them. More like; this difference is mentioned in differentiating traditional music forms each others.

It was also seen to be added that eleven syllable poems were mostly written on these epic bases as a result of different events. According to these regulations, the subjects covered were mainly love, pain, death, expatriation, longing and separation. There is the extension of the tenth syllable which is performed in the two and fourth lines among the noticeable vocal characteristics of the characteristic epic pedestal. Rhythm pattern in traditional Ardeşen epics is aaab. In this order, there are mostly stops in the sixth syllable. The local expression of the epics in the region is Destani.

Keywords: Folk music, Epic, Ardeşen.

\section{Giriş}

Müzikoloji; müzikle ilgili her türlü bilgi bütününün incelendiği bir çalışma alanıdır. Bu çalışma alanı, bilgi edinilmek istenen konuya göre alt dallara ayrılmaktadır. Geçmişte var olmuş ve aydınlatılmamış olan müzik verilerini ya da aydınlatılmış olup üzerinde çalışılması gerektiği düşünülen 
müzik verilerini toparlayan, analiz eden ve yorumlayan müzikoloji dalı, tarihi müzikolojidir. Bir müzik uygulamasının teorik olarak ortaya konması ile ilgili olan ve bu teorinin eğitim ve öğretim maksatlı olarak da kullanılabilirliğini inceleyen müzikoloji disiplini ise sistematik müzikoloji adını alır. Sistematik müzikoloji diğer bir deyişle müzik pratiklerini kuramsallaştıran bir alt daldır. Müzikolojinin diğer bir alt dalı da disiplinler arası müzikolojidir ki bu da; müzikle ilgili bilgi bütününü, farklı bilim dalları ile bütünleştiren bir yapıyı ifade eder. Edebiyat, sosyoloji, psikoloji, antropoloji, arkeoloji, tarih, coğrafya, tıp ve halkbilimi gibi birçok disiplin, müzik araştırmalarına yardımcı olan ve bu manada müzikolojinin ihtiyaç duyduğu verilere ulaşmamızı sağlayan önemli alanlardır. Bu alanlar içerisinde halkbilimi, müzikolojiye yardımcı olması anlamında kayda değer bir yere sahiptir. Halk müziği araştırmaları ise kültürel anlamda halkbiliminin vazgeçilmez unsurlarındandır.

Ülkemiz, kültürel açıdan birç̧ok farklı uygarlığın birleştiği, birlikte yaşadığı ve etkileşim içerisine girdiği çok zengin bir coğrafyadadır. Bu etkileşim; pek çok farklı alanda etkisini göstermiş ve göstermeye de devam etmektedir. Geleneksel anlamda da müzik kültürümüz yaşayış biçimleri, inanışlar, örf ve adetler gibi birçok parametreye göre bölgeden bölgeye, yöreden yöreye, hatta köyden köye değişiklik gösterebilmektedir. Doğu Karadeniz Bölgesinde de müzik kültürü bağlamında birçok farklı geleneğin etkili olduğu açıktır. Bu farklı gelenekler, bölgede geçmişte yaşamış ve halen yaşayan insan topluluklarının müzik üretimini ve karakteristiklerini etkilemiştir.

Türkiye'de müzikoloji alanında yapılmakta olan çalışmalar artmaktadır fakat halk müziklerinin sınıflandırılması anlamında, özellikle Doğu Karadeniz bölgesinde yaşayan müzik kültürünü ortaya koyan çalışmaların yeterli olmadığı görülmektedir. Çalışmalar incelendiğinde genel olarak Trabzon, Rize ve Artvin yöresi ile ilgili araştırmalar bulunmaktadır. Ancak; gerek halk müziğinde tür ve biçim anlamında, gerekse yörede yaşayan toplulukların müzik üretimini birbirinden ayırma ve sınıflandırma anlamında bir çalışma bulunmamaktadır. Doğu Karadeniz bölgesinde bulunan geleneksel müzik kültürünün yörelere göre farkl1lık gösterdiği ve bu farklılı̆̆ın Ardeşen yöresi kapsamında da değerlendirilmesi gerektiği düşüncesinden hareketle, ortaya konması ve çözümlenmesi gereken durumlar olduğu düşünülmektedir. Yörede yaşayış biçimleri incelendiğinde farklı müzikal tür ve biçimlerin bulunacağı öngörülmektedir. Ayrıca; müzikoloji bilimi çerçevesinde alanda yapılmasının gerekli olduğunu düşünülen çalışmaların; halk müziği verilerini bulma, ortaya koyma ve arşivleme ile nitelikli hale getirilmesi gerekmektedir. Bu halk müziği verileri, kaynağındaki çalış ve söyleyiş üslubunu aktaran ve derleme teknikleri ile yapılandırılmış bir biçimde toplanan veriler olmalıdır.

Çalışmanın genel amacı; ülkemizdeki müzik değerlerinin ulusal ve uluslararası alanda tanıtılmasına katkı sunmaktır. Bu çerçevede belirlediğimiz özel amaç ise; Ardeşen yöresi müzik kültüründe yer alan destan türü ile ilgili ses kayıtlarına ulaşılması, derleme çalışmaları sonucunda elde edilen ses kayıtlarının arşivlenmesi ve çeşitli analizlerinin yapılmasıdır. Doğu Karadeniz Bölgesi illerinin bazı yörelerine ait müzik kültürü ile ilgili yapılmış çalışmalar bulunmakla beraber, bu çalışmaların bölgenin müzik kültürünü tam olarak ifade edemediği düşünülmektedir. $\mathrm{Bu}$ açıdan bakıldığında bölgenin doğu kesimlerindeki müzik kültürü; gerek melodik ve ritmik yapı gerekse kullanılan dil ve çalg1 türü bakımından oldukça farklı bir yapı sergilemekte olduğundan; yapılan çalışma, bu farklılığı ortaya koyması anlamında ayrı bir önem arz etmektedir.

\section{Yöntem ve Teknik}

Bu çalışma, ağırlıklı olarak katılımcı gözlem ve deneyimleme esaslarına dayandığı için nitel araştırma yöntemi kullanılarak gerçekleştirilmiştir. Aynı zamanda geçmişe dönük tarama araştırmaları da yapılarak, betimlemelerin kolaylaştırılması sağlanmıştır. Araştırmanın modeli, alan araştırması modelidir. "Alan araştırması, araştırmacının "alan" olarak tanımladı̆̆ 1 yerde görerek, duyarak, gözlemleyerek, katılarak bilgi edinmesi ve böylece eylemlerin, sözel ifadelerin, kısaca topluluğu saran tüm olay ve olguların anlamlarına vakıf olma çabasıdır. Alan araştırması; alan öncesi, alanda geçirilen süre ve alan sonrasıyla birlikte ilerleyen, birbirine bağlı ve birbirini belirleyen süreçlerden 
oluşur”'(Karahasanoğlu ve Yavuz, 2015, s. 59,60). Günümüzde alan araştırması, sadece kırsalda yapılan gözlem, katılımcı gözlem ve görüşmelerden ibaret değildir. Gelişen teknoloji ve iletişim ağının yaygınlaşması, internet üzerinden bilgiye ulaşma yollarının ortaya çıkması, alan araştırmasını sanal ortamlarda da desteklemektedir.

Nitel bir çalışma olan bu alan araştırmasında; kişilerle yapılmış olan derinlemesine ve yüz yüze görüşmelerin, kaynak kişi belirlemelerinin, alanda yapılan gözlemler ve kayıt altına alınmış olan verilerin ne şekilde toplandığı hakkında bilgi verilecektir. "Derleme; bir geleneksel kültür ortamında yerel ses kültürünün tüm verilerini özgün metot ve teknikler kullanarak toplama işidir. Derleme çalışmaları yapan gruplar, daha çok yerel müzik kültürlerinin çeşitli öğeleri üzerinde, mekân olarak ise kırsal alanlarda çalışmaya özen gösterirler. Bu tip bir derleme anlayışı daha çok folklorcuların tercih ettikleri bir çalışma biçimidir" (Duygulu, 2014, s. 142). Derleme en geniş anlamıyla; halkbiliminin çalışma kapsamında bulunan halk sanatı ürünlerini asıl membaından titiz bir şekilde alıp belgelemeyi, muhafaza etmeyi ve ilelebet var olmalarını sağlamayı amaçlayan bir iştir. Halk müziği verileri açısından ise derleme; anonim özellikteki kırsal müzik verilerinin sözlü ya da sözsüz oluşuna bakılmaksızın özgün ve akademik bir titizlikle kaynağındaki çalma, söyleme üslubuna sadık kalarak toplamak, belgelemek ve değerlendirmek olarak tanımlanabilir.

Yörede yapılan kaynak kişi belirlemeleri, geleneksel çalış ve söyleyiş üslubunu en iyi aktarabilen kişiler arasından seçilmiştir. Bu seçim yapılırken bölgenin ileri gelenlerine danışılmış, geleneksel müzik çevrelerinde profesyonel olarak çalışan kişilerden de bilgi alınmıştır.

Çalışmada kullanılan veri toplama tekniklerinden birisi gözlem tekniğidir. Gözlem tekniğinin kullanılmış olmasındaki amaç, ilk elden veri toplanmasına katkı sunabiliyor olması ve tekrar edilme durumunun gözlemciye bağlı olarak arttırılabilmesidir. "Nitel araştırmalarda gözlem bireysel bir deneyimdir; araştırmacının becerisi, bilgisi ve deneyimi ile şekillenir. Gözlemin bileşenleri, yani fiziksel çevre, mekân, nesneler, aktörler, cinsiyetler, dış görünüssler, benimsenen roller, rutinler, zaman, hatta sesler ve duygular nitel araştırmalarda daha önemlidir"(Karahasanoğlu ve Yavuz, 2015, s.18). Sözel olmayan verilerin toplanması ile ilgili olarak dışarıdan gözlem yapılması düşünülmüş, uygulamalardaki gerçek tavrı anlayabilmek için ise katılımlı olarak gözlem yapılmıştır. "Gözlemci rolüne göre daha fazla zaman ve emek isteyen katılımcı gözlem, en genel tanımıyla araştırmacının olayların ve topluluğun dışında kalan biri oluşundan, topluluğun içine dâhil olunmasına vurgu yapar"(Karahasanoğlu ve Yavuz, 2015, s.66). Katılımcı gözlemci olunmasının en büyük avantaj1, topluluğun doğal üyesi olmaktır. Bu şekilde hem gerçekte olan veriler toplanabilmiş, hem de gözlemler, etik kaygılardan arındırılmış olarak kayıt altına alınabilmiştir. Araştırmacının yöre topraklarında doğmuş olması, bölge insanını yakından tanıması bilgi toplama sürecini kolaylaştırmıştır.

"Nitel veri analizi, araştırmacının verileri düzenlediği, analiz birimlerine ayırdığı, sentezlediği, biçimleri ortaya çıkardığı, önemli değişkenleri keşfettiği ve hangi bilgileri rapora yansıtacağına karar verdiği bir süreçtir” (Boğdan ve Biklen'den aktaran Özdemir, s. 328). Bu tanıma göre ortaya çıkan bazı aşamalar olmalıdır. Bu aşamalar çalışmada birbirini sıralı bir şekilde takip etmiştir. İlk olarak elde edilen verilerin hangilerinin çalışmada kullanılması gerektiği tespit edilerek veri azaltma işlemi sağlanmıştır. Buradaki kasıt, birbirine yakın olan ses kayıtlarının elenmesidir. Sonrasında verilerin görsel hale getirilmesi işlemi yapılmıştır. Buradan da ses kayıtlarının notaya aktarılması ve resim formatına dönüştürülmesi anlaşılmalıdır. Böylece verilerin bilimsel olarak gösterimi işlemi tamamlanmış olmaktadır. Son olarak yapılan işlem, sonuç ve teyit ile ilgili işlemlerdir. Bu aşamada bütün süreci anlamlandırmaya yönelik bir tutum sergilenerek sonuca ulaşılmıştır. Araştırma verilerine ulaşıldıktan sonra görüşme ve gözlem kayıtlarındaki bulgular bire bir yazılmıştır. Bu aşamadan sonra ise bulgular düzenlenerek yorumlanmaya çalışılmıştır. Araştırmanın alt problemler kısmına ilişkin oluşturulmuş temalarla birlikte veriler, bir sınıflandırmaya tabi tutulmuş ve bu kapsamda değerlendirilerek betimsel analiz yöntemiyle işlenmiştir. "Betimsel analiz, çeşitli veri toplama teknikleri ile elde edilmiş verilerin daha önceden belirlenmiş temalara göre özetlenmesi ve yorumlanmasını içeren bir nitel veri analiz 
türüdür. Bu analiz türünde araştırmacı görüştüğü ya da gözlemiş olduğu bireylerin görüşlerini çarpıcı bir biçimde yansıtabilmek amacıyla doğrudan alıntılara sık sık yer verebilmektedir. Bu analiz türünde temel amaç, elde edilmiş olan bulguların okuyucuya özetlenmiş ve yorumlanmış biçimde sunulmasıdır" (Yıldırım ve Şimşek, 2003).

Bu çerçevede elde edinilen bulgular öncelikle edebi ve müzikal yönden değerlendirilmiş, daha sonra tanımlanmış ve son olarak da yorumlanmıştır. Gözlem ve görüşme sonuçlarına göre elde edilen müzik verileri öncelikle notaya aktarılmış, daha sonra fişleme metodu ile belgelenmiştir. Notalama işlemine geçmeden önce verilerin azaltılması bölümünde, müzik ve ses ayrıştırıcı bir program olan Mixcraft programı kullanılarak ilgili verilerin kısaltılma işlemleri yapılmıştır. Bu kısaltma işlemi, görüşme kayıtlarında elde edilen bireysel açıklama, tanımlama, hikâye anlatımı gibi bölümlerden, notaya aktarılması gereken ses verilerinin ayrıştırılması olarak da ifade edilebilir. Dolayısı ile yalnızca transkripsiyonu yapılacak olan veriye ulaşılmıştır. Bu sayede notaya aktarma işlemleri daha sağlıklı olarak gerçekleştirilmiş̧ir. Fişleme metodu ile hazırlanan belgelerde; müzik verisi ile ilgili kaynak kişi bilgileri, yöre ile ilgili bilgiler, halk müziğinde tür ile ilgili sınıflandırmalar da yer almıştır. Transkripsiyon ile ilgili olarak bilgisayarda nota yazım programlarından olan Mus 2 ve Finale nota yazım programları kullanılmıştır.

\section{Ardeşen Yöresi Halk Müziğinde Destan ve Destancılık Geleneği}

Etimolojik olarak incelendiğinde destan kelimesinin Türkçeye Farsçadan (dastan) geldiği bilinmektedir (Oğuz, 2004, s. 130). Sözlükte destan kelimesi, "1. Tarih öncesi tanrı, tanrıça, yarı tanrı ve kahramanlarla ilgili olağanüstü olayları konu alan şiir, epope...2. Bir kahramanlık hikâyesini veya bir olayı anlatan, koşma biçiminde, ölçüsü 11 hece olan halk şiiri. 3. Çağdaş Türk edebiyatında biçim ve içerik yönünden geleneksel destanlardan ayrılık gösteren uzun kahramanlık şiiri...(Türkçe Sözlük, 1988, s. 63) olarak tanımlanmaktadır.

Ardeşen ilçesi geleneksel müzik kültüründe destan türü ile ilgili özel bir telaffuz bulunmamaktadır. Yöre ağzına "destani” olarak girmiştir. Kelime manası olarak da öykü, masal ve ün gibi anlamları içererek birçok yörede kahramanlık, yiğitlik, ölüm ve afet gibi konuları kapsayan mensur veya manzum halde yazılmış anlatı geleneğinin genel adı olarak yer bulur. Melih Duygulu, Türk Halk Müziği Sözlüğünde destan hakkında şu açıklamalara yer vermektedir: "Çeşitli konuların hikâye edildiği, daha çok koşma biçiminde yazılan / söylenen uzun şiir katarlarına verilen isimdir... Halk arasında Anadolu'da tarihi ve mitolojik nitelikli destanlardan çok, yakın geçmişte olan ve toplum vicdanında iz bırakmış olaylar üzerine yazılmış / söylenmiş destanlar yaygındır. Hemen her türlü doğal ve sosyal olayı konu edinen destanlara halk edebiyatı ve müziğinde rastlanabilir... Şiir katarlarından oluşan destanlar ezgiyle veya sadece dilden söylenebilir... Destan eğer söylenmenin yanı sıra saz eşliğinde icra edilirlerse, icracının çalım gücüne ve dağarcığına bağlı olarak değişen saz partileri, destanın başında, ortasında ve son kısmında çalınır. Bu saz partileri çoğunlukla serbest tartımlı bazen de ritmik kalıpları belirgin ezgilerden oluşur ki buna "destan ayağı" adı verilir. Destancılar, kendilerine özgü yerel ezgi kalıplarıyla çoğunlukla da serbest tartımlı bir ezgi ile destanlarını seslendirirler. Burada müzikal yapı, destanın söylendiği / yazıldığı yörenin müzik kültürünün dışına çıkmaz. Bir kısım gezici destancılar gittikleri yörenin müzik karakterine uygun ezgi kalıplarıyla destan söyleyebilirler" (Duygulu, 2014, s. 143-144).

Ardeşen ilçesinde tarafımızdan yapılan araştırmalara göre geleneksel destan türünde; Duygulunun açıklamalarından farklı olarak, destanın anlatı bölümleri tamamen müzikal icra ile birlikte yer almaktadır. Ardeşen ilçesinde geleneksel destan türünün konuları arasında aşk, hastalık, ayrılık, ölüm, gurbetlik, göç, afet, geçim sıkıntısı gibi olaylar yer alırken; en sık karşılaşılan konuların başında aşk ve ölüm gelmektedir. Tarihi süreçte Ardeşen ilçesinde yetişmiş destancılardan bahsedilmektedir. Bu destancılar bir nevi halk aşığı/ozanı olarak da nitelendirilmektedir. Söz sanatlarının icrası konusunda yeterlilikleri şüphe götürmeyen bu kişiler, yöre insanı tarafından benimsenmiş, belirli icra ortamlarında 
yer tutmuşlardır. Destancılar, sanatlarını icra ederken yalnızca kendi yaşadıkları olayların sonuçlarını değil başka insanların duygularını da onların söyleyişinden aktarabilmektedirler. Âşıklık geleneğindeki gibi çok detaylı olmasa da burada da bir usta - çırak ilişkisinden de söz edilebilir. İlçede görüşülen kaynak kişilerden edinilen bilgilere göre bazı destanlar yazıya geçirilmiş, bazıları ise yazıya geçirilememiştir. Destancıların varlığı ile ilgili olarak Gedikoğlu'nun açıklamalarına yer vermek doğru olur: "Doğu Karadeniz Bölgesinde 1970'lere kadar çarşı pazar dolaşarak yüksek sesle okuya okuya destan satan destancılar vardı. Onlara "destancı" denirdi. Her destancının kendine özgü bir destan okuma ezgisi olurdu. Bu ezgilerin kimileri zamanla anonimleşir, başka destancılarca da benimsenirdi. Başlangıçta çıplak sesle okunarak satılan destanlar, megafonlar çıkınca megafonlar, kasetli ses alıcıları yaygınlaşınca da ses düğmesi sonuna kadar açılan teypler aracılığıyla satılmaya başlandı. Destancılar ya kendilerinin ya da başkalarının ürettiği tek yapraklı destan kâğıtlarını boyunlarına astıkları çantaya tomar tomar doldurup, haftanın her günü ayrı ayrı kurulan pazar yerlerinde satarak geçimlerini sağlamaya çalışırlardı. İletişim araçlarının gelişmesi, destancıların da destanların da sonunu getirdi” (Gedikoğlu, 2008, s. 170).

Yukarıda sözü edilen destancılık geleneği ile ilgili bilgilere alan araştırması esnasında da rastlanmıştır. Ne yazık ki sözü edilen eski dönemlerde okunan destanlar arşivlenememiştir. Yazılan destanların şiirde biçim açısından incelenmesi gerekirse halk şiirinin dörtlük nazım biriminde ve hece ölçüsü olarak da on birli ölçüyü kullandıkları görülmektedir. Hece durakları ise kullanılan ezgi kalıbına göre değişebilmektedir. Destan türünde kafiye düzeni a a a b şeklindedir. Kıta sayıları ise değişmekte olup, kırk dörtlüğe kadar çıkabilmektedir. Yörede derlenen birçok destanın ezgi kalıbı aynıdır. Ancak bazı köylerde kalıba bağlı kalınarak okuyuş üslubunda değişmeler görülebilmektedir. "Lazlarda destan geleneği sözlü edebiyatın en önemli öğesidir. Yazılı gelenek olmadığı için dilden dile, kulaktan kulağa, kuşaktan kuşağa sözlü aktarılarak günümüze taşınmıştır. Çoğunda dörtlü kıta yapısı vardır. Satırlar bazen on bir hece ile bazen de yedi hece ile oluşturulmuştur. Dörtlük sayısının kimi zaman konulara göre, kimi zaman da söyleyenlere göre değiştiği gözlenmiş̧ir. Destanlarda kullanılan ezgiler genelde aynı olup, bu ezgiler söyleyen kişinin yorumuna göre küçük nüanslarla değişebilmektedir. Günümüzdeki Laz destanları iki grupta incelenebilir. Birincisi, (büyük bölümü oluşturan grup) yazarı ya da yazarları bilinmeyen anonim destanlar. İkincisi yazarı bilinen destanlardır. Destanlar tulum ve kemençe gibi bir çalgi aleti eşliğinde söylendiği gibi, çoğu durumlarda çalgısız olarak da söylenir. Destanlar genelde aşk üzerine söylenmiş gibi olsa da, aşk ve sevda dışında da istisna sayılmayacak kadar destana rastlanır" (Aksoylu, 2010, s.141).

Etnomüzikoloji araştırmalarından bilindiği üzere geleneksel halk müziklerindeki sözlü ezgiler, o yörede kullanılan çalgıların ses sahaları ile ilişkili olarak şekil almaktadırlar. Destanlarda kullanılan ses sahası da, bölgede kullanılan tulum ve kemençe çalgısının ses sahalarına göre biçimlenmiştir. Ardeşen ilçesinde en sık kullanılan çalgı olan tulumun sınırlı ses sahası sebebiyle bazı destanlarda yalnız hüseyni ve uşşak sesleri kullanılmaktadır. Yalnız bazı kaynak kişilerden edindiğimiz kayıtlar göstermektedir ki; kemençe ile çalınan destanlarda hicaz ve saba gibi makamlar da hüseyni seslerine ek olarak kullanılabilmektedir. Hatta alanda karşılaşılan bir durumdan da bahsedilmesi gerekir ki bu da, destanı yazan kişinin kullandığı seslere göre çalgısını seçtiği gerçeğidir. Eğer destan söyleyen kişinin destan kaidesi uygun ise, destanı tulum eşlikli olarak söylemektedir. Fakat uygun değil ise yani farklı sesler içeriyorsa, çalgısız ya da kemençe eşliğinde söylemektedir. Nitekim kemençenin ses sahası tulumun ses sahasından daha geniş ve çeşitlidir. Ardeşen ilçesinde yapılan derlemeler sırasında destanların ezgi kalıplarının çok değişmediği görülmektedir. Birçok destan tek bir ezgi kalıbı ile söylenmektedir. Çalışmada bu ezgi kalıbına "karakteristik destan kaidesi" ismi verilmiştir. Destan kıtalarının ikinci ve dördüncü satırlarında bulunan onuncu hecenin, destanı okuyan kişinin isteğine bağlı olarak uzatılarak on birinci heceye bağlanması durumu, bölge içerisindeki geleneksel müzik türleri arasında destanı farklı bir yere koymaktadır. 


\section{Ardeşen Yöresinde Derlenen Destanlar ve Transkripsiyonları}

Yörede derlenen destanlarda karakteristik bir ezgi kalıbı bulunmaktadır. Bu ezgi kalıbı, köyden köye üslup ve tavır bakımından küçük farklar gösterebilmektedir. Derlenen destan dörtlükleri, on birli hece ölçüsü ile yazılmıştır. Hemen hemen bütün dörtlüklerde ikinci ve dördüncü mısraların onuncu hecesinde uzun süreli bir okuyuşa rastlanmıştır. Bu durum müzikal olarak da ifade edilmiştir. Yapılan kişisel görüşmelerde destan dörtlüklerinin çoğunlukla bir karakteristik ezgi ile okunduğu görülmüştür. Buna ek olarak yörede yapılan çalışmada, farklı iki ezgiyle daha karşılaşılmıştır. Bu ezgilerin kişisel üretimler olduğu düşünülmektedir. Destanlarda kıta sayısı değişebilmektedir. Yalnızca tek dörtlükten oluşan destanlar olabildiği gibi sayısı kırka varan destanların da bulunduğu, alanda yapılan görüşmelerde tarafımızdan tespit edilmiştir. İlgili kaynak kişi bu destanların varlığından bahsetmekte fakat ezberinde kırk dörtlükten oluşan bir destanın tamamının olmadığını da belirtmektedir. Aşağıda verilen metinlerin tek bir destan kaidesi ile söylendiği tespit edilmiştir.

\section{Askerlik Destanı}

(1)

Sali sabah ile evden yurudum

Pazar'dan herkese selam göturdum

Sirkeci Konak’ta üç gün kalmişim

Ana baba hasret ile yanmişim

Erukler yetişti yeyun yalanuz

Ana baba hasretiyle kalmanuz (Saral, S)

Yukarıdaki destan metninde yörede yaşamış merhum Hamdi Saral'ın askere gittikten sonra ailesine yazdığı mektupta bulunan hasret dolu sözler, oğlu Salih Saral tarafından 2018 Temmuz ayında tarafımıza aktarılmıştır. Destan metninden anlaşılmakta olan, ailesinden ayrılmakta olan bir gencin duygularının ifadesidir. Söz konusu metinde memleket hasreti, hasat zamanına atıfta bulunularak ifade edilmiştir. Aşağıda kaydedilen destan sözleri ise; Ardeşen ilçesi merkezinde yaşayan Ali İhsan Şişmanlar adlı kaynak kişiden derlenmiştir. Destanda, oğlunu kaybetmiş bir annenin acıları anlatılmaktadır. Bahsedilen olayda yüzmeye dereye giren bir gencin boğularak can vermesi konu edinilmiştir. 15 Temmuz 2018 tarihinde Ardeşen ilçesinde yapılan görüşmede, olayın tarihinden bahsedilmemiştir. Ancak metin, yörede kuşaktan kuşağa aktarılmış ve anonim bir yapı kazanmıştır.

\section{Gül Ali Destanı}

(1)

Çikamadum Çopukli'nun duzina

Gelin edup bakamadum yüzina

Nişan verdum emicamun kizina

Gülali’m Gülali'm ağ oğul oğul
(2)

Ağustos on alti Cuma ertesi

Kurusun bu Yaylacilar deresi

Yavrumun yuzmağa vardi hevesi

Gülali’m Gülali’m ağ oğul oğul 
(3)

Yavrum yarum saat gölde kaldun mi?

Oğul nefes alup veremedun mi?

Ana baba diye diyemedun mi?

Gülali'm Gülali'm ağ oğul oğul

Oğul gül çiçeğum sarilalum mi

Bugün son günümüz ayrilalum mi?

Kiyamete kadar darilalum mi

Gülali’m Gülali’m ağ oğul oğul

Çiktum yaylalara gördüm kurd izi

Koyunlar bağirur aradan kuzi

$\mathrm{Bu}$ sene karişti yaz ile güzi

Yaradan göndersa sizi olmaz mı
(4)

Çopukli'nun başi salma tepesi

Poçkut'tan duyulur tangolun sesi

Tükendi kalmadi sondur nefesi

Gülali’m Gülali’m ağ oğul oğul

(6)

Ah ana ah baba deyemeyince

Suda nefes alup veremeyince

Çırpınup yukari çikamayince

Kaldum baş aşağı ah oğul oğul

(8)

Geze geze geldum dağun beline

Nasıl düştüm ezrailun eline

Ömer fişekluği sarmış beline

Validesi göremedi neyleyim (Şişmanlar, A)

Ali İhsan Şişmanlar kaynak kişisinden, 16 Temmuz 2018 tarihinde Ardeşen ilçesinde derlenen diğer destan metinleri aşağıda verilmiştir. Buna göre metinlerde işlenen konuların sevdalık, hastalık ve ölüm olduğu tespit edilmiştir.

\section{Sevdaluk Destanı}

Sevduğum entaren sari kumaştan

Sevda ettun beni çikardun baştan

Hayır görmeyesen o sari saçtan

Gel nazli sevduğum ağlatma beni

Kimse bilmiyor hali ahvali

Gözuma gelmiyor dunyanun mali

Tuttuğum ağacun kırıldı dali

Geçmiyor bu günler acıtma beni
(2)

$\mathrm{Bu}$ bir bela idi geldi başuma

Verem olacağim be genç yaşuma

Derdumi anlatsam arkadaşuma

Sabrın sonu gelmez ağlatma beni

(4)

Birbirinden ala göz ile kaşi

Hemen on sekizi buliyor yaşi

İstedum vermedi zalim kardaşi

Yandi ciğerlerum dondi piyazi (Şişmanlar, A.) 


\section{Hastalık Destanı}

(1)

Cumaa sabahi duştum Ğere'ye

Buğday aldum dondum Oce dereye

Oce'den sevk oldum geri Rize'ye

Rize'de Ezrail meydan vermedi
(2)

Rize’ye göturma dedum Kazim'e

Niye kulak vermiyosun sözüme

Selam olsun oğlanume kizume

İki gündür kahpe felek gülmedi (Şişmanlar, A.)

11.01.2002 tarihli ve Osman Zeki Tekin tarafindan kaleme alınan destan, Fırtına Deresi'nde hayatını kaybeden bir gencin babasının ağzından söyleniyormuş gibi yazılmıştır. Osman Zeki Tekin, yörede yazdığı şiirlerle tanınan bir kaynak kişidir.

\section{Osmanişi Destani}

Dikkaya'dan indi dere boyuna Olta $\mathrm{m} 1$ atarsın ölüm suyuna Yuttu Osman'ı mı azgin Firtına Dayanır mı yürek böyle acıya

Dere boylarında ararım oğul Acın alev oldu yanarım oğul

Çırpınır İnsanlar önünü keser Bulunmaz yavrumdan bir parça eser Evimizin önü sanki bir mahşer Sevenlerin gelmiş gözyaşı döker

Fırtına ağzında beklerim oğul Gözümden yaşları dökerim oğul

Ey zalim Firtına inat edersin Osman'ı mı bana geri vermezsin Bir bilsem ki oğul nerede yatarsın Bin bir acımıza acı katarsın

Deniz kıyısını gözlerim oğul Baba deyişini özlerim oğul

Daha yeni girdin om üç yaşına Duyanlar ağllyor boğuluşuna Yürek mi dayanır bu gözyaşına Ben de ölsem oğul senin peşine
(2)

$\mathrm{Bu}$ ne gaflet oğul geldin oyuna

Kara haber tez ulaştı köyüne Vermez Osman'ı mı azgın firtına $\mathrm{Bu}$ acıya hangi yürek dayana

Dere boylarında ağlarım oğul Acınla yüreğim dağlarım oğul

Kara haber her tarafa yayıld 1 Annen nerede yavrum diye sarıldı Sirtımda koca bir kambur belirdi Sevenlerin hep yollara serildi

Fırtına boyunda ararım oğul $\mathrm{Bu}$ acı kadere yanarım oğul

Deniz kıyıları bir bir arand1 Bulunmaz Osman'ım çare kalmadı Hicran oku yüreğime saplandı El açtım Mevla'ma çilem dolmadı

Seni her yerlerde ararım oğul Saçın bir teline yanarım oğul

Anası figan da ağıtlar yakar Ac1 sele dönmüş bendini yıkar Daha yaşı on üç hemi de bekâr Evladım acısı yüreğim yakar 
Deniz boylarını gözlerim oğul

Anne deyişini özlerim oğul

(10)

Bu azgın Fırtına büyük bir dere

Nice İnsanımı yuttu çok kere

Sen de yakalandın oğul ecele

Feryat figan yetmez böyle kadere

Köşe bucak seni ararım oğul

Acın alev oldu yanarım oğul

Yok ki bir mezarın çiçek dikeyim

Ara sira yavrum diye öpeyim

Öpeyim de gözyaşımı dökeyim

Bayram günlerinde gelip koklayım

$\mathrm{Bu}$ acıya yürek dayanmaz oğul

Evlat acısıyla yaşanmaz oğul
Beni yerden yere atarım oğul

Acın alev oldu yanarım oğul

Aylarca aradım iz bulamadım

Gelsem sana dedim yol bulamadım

Dar imiş mezarlık yer bulamadım

Yıllar geçti oğul haz alamadım

Dere boylarında ağlarım oğul

Senin yokluğuna yanarım oğul

(13)

Evladımla bir tutarım Osman'ı

Âşık Osman yazdı sana destanı

İki evlat gömdüm kaderim aynı

Evlat acısına bir çare var mı

Ben de senin gibi yanarım dostum

Yıllardır yasını tutarım dostum (Tekin, O.)

Yukarıda verilen destan metinlerinin, aşağıdaki nota ile okunduğu tespit edilmiştir. Genellikle bölgedeki ağıtlar da bu ezgi ile söylenmektedir. Karakteristik destan kaidesi olarak tespit edilen aşağıdaki ezgi, ritmik yapı bakımından dört dörtlük ölçüyle uyum sağlamaktadır fakat yöredeki icracıların seslendirme aşamasında, serbest ritim de kullandıkları görülmüştür. Görüldüğü üzere donanım, bir koma si bemol sesi içermektedir. Bu durum, kullanılan makamların hüseyni ya da uşşak dörtlüsü/beşlisi olduğunu göstermektedir. La duraklı olarak yazılan melodilerde, icracının kendi kişisel üslubuna bağlı olarak bazı derecelerde asma kalışlar görülmüştür. Bunlar re ve la seslerinde uygulanmıştır.

\section{Karakteristik Destan Kaidesi}

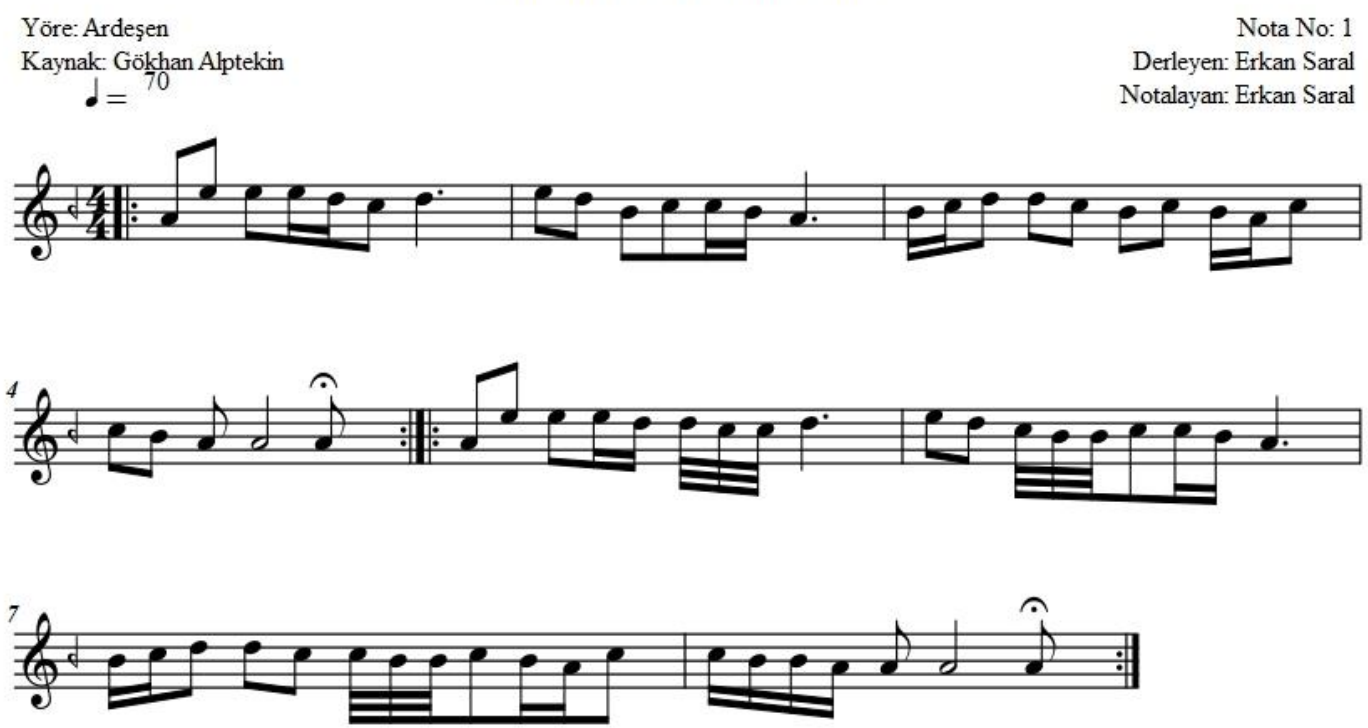

Yörede destan niteliği kazanmış bir başka ezgi, "yol havası" olarak da bilinmektedir. Halk arasında genel olarak bu ezgilere de destan kaidesi denmektedir. Derlenen bu sözlerin, söyleyen kişinin 
yaşadığı olaylara ve buna bağlı olarak hissettiği duygulara bağlı olarak değişebildiği tespit edilmiştir. Orhan Ayata'dan derlenen bir yol havası örneği aşağıda verilmiştir.

Yayladan Enen Atlar
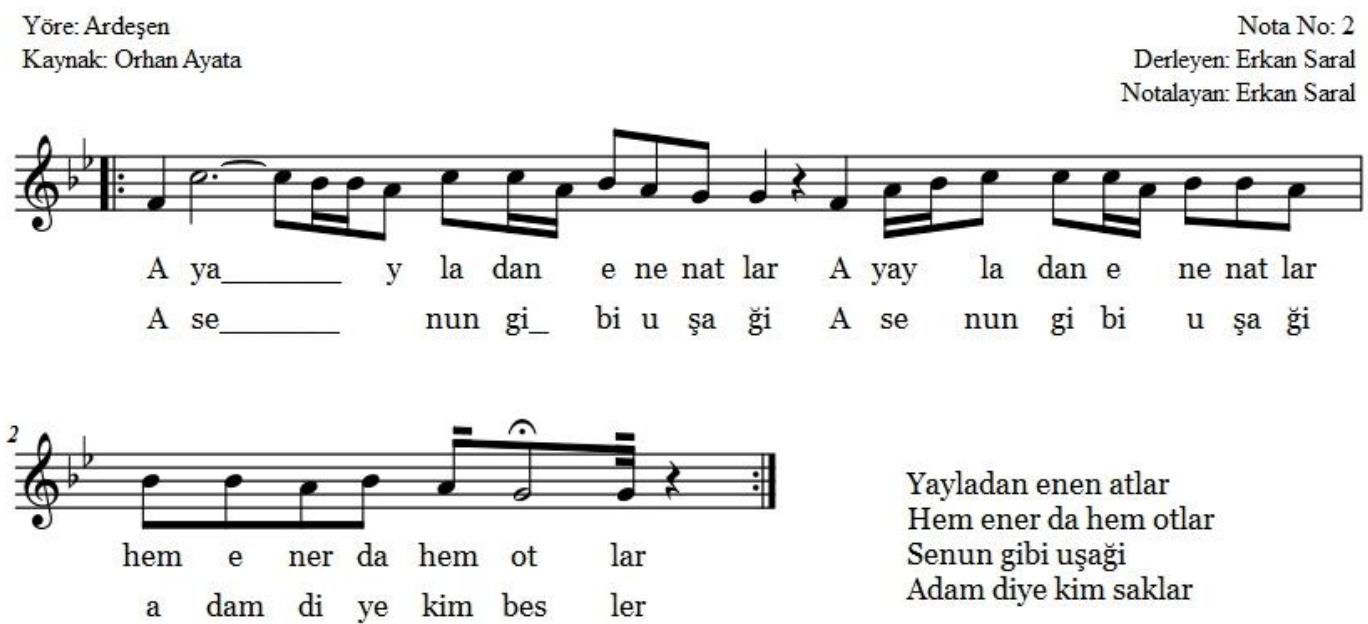

18 Temmuz 2018 tarihinde Ardeşen ilçesi Müftü mahallesinde Asiye Ayata'dan derlenen ve ayrılık üzerine yazılan bir başka destanın sözleri aşağıda kaydedilmiştir. Verilen görüşme kaydına göre, Rusya'ya çalışmak için giden bir gencin, Moskova'da teröristler tarafından öldürüldüğünden bahsedilmiştir. Destanın içerisinde geçmekte olan "Açma dağlar çiçek ağlatma beni” sözleri, yörede geleneksel olarak kullanılan bir ağlama ifadesidir. Bu sözler, genellikle sayma, ağlama, ses verme olarak bilinen ağıt türünde de kullanılmaktadır.

\section{Açma Dağlar Çiçek Ağlatma Beni}

(1)

Moskova dağinun çoktur dumani

Teroristun yoktur dini imani

Tez gel yavrum bekleyirum yollari

Açma dağlar çiçek ağlatma beni

Yaşum onaltiye varum varmadan

Gül toprağa girmem seni almadan

Açma dağlar çiçek ağlatma beni

(5)

Evumun oninde soğuk su akar

Yaniyor yureğum canlari yakar

Aci destan yazdum canumi yakar

Açma dağlar çiçek ağlatma beni (Ayata, A.)
(2)

Ağlaya ağlaya yaşum kurumaz

Karadur ikbalum şansum yurumaz

Tez gel yavrum bekleyirum yollari

Açma dağlar çiçek ağlatma beni

Cumaa cunidur Ğere pazari

Seni alamazsam kazun mezari

Açma dağlar çiçek ağlatma beni (Ayata, O) 
Aşağıda notası verilen destan kaidesinin, karakteristik destan kaidesinden farklı olduğu tespit edilmiştir. Buna rağmen geleneksel ezgide daha önce belirtilen ikinci ve dördüncü mısrann onuncu hecelerindeki uzatmalara bu metinde de rastlanmıştır. Ezgi uşşak dörtlüsü içermektedir. Karar perdesi dışında uzun süreli kalışların bulunduğu sesle karşılaşılmamıştır. Yalnız ezginin ikinci derecesinde, mısra geçişleri ile ilgili olarak kısa süreli kalışların bulunduğu görülmüştür.
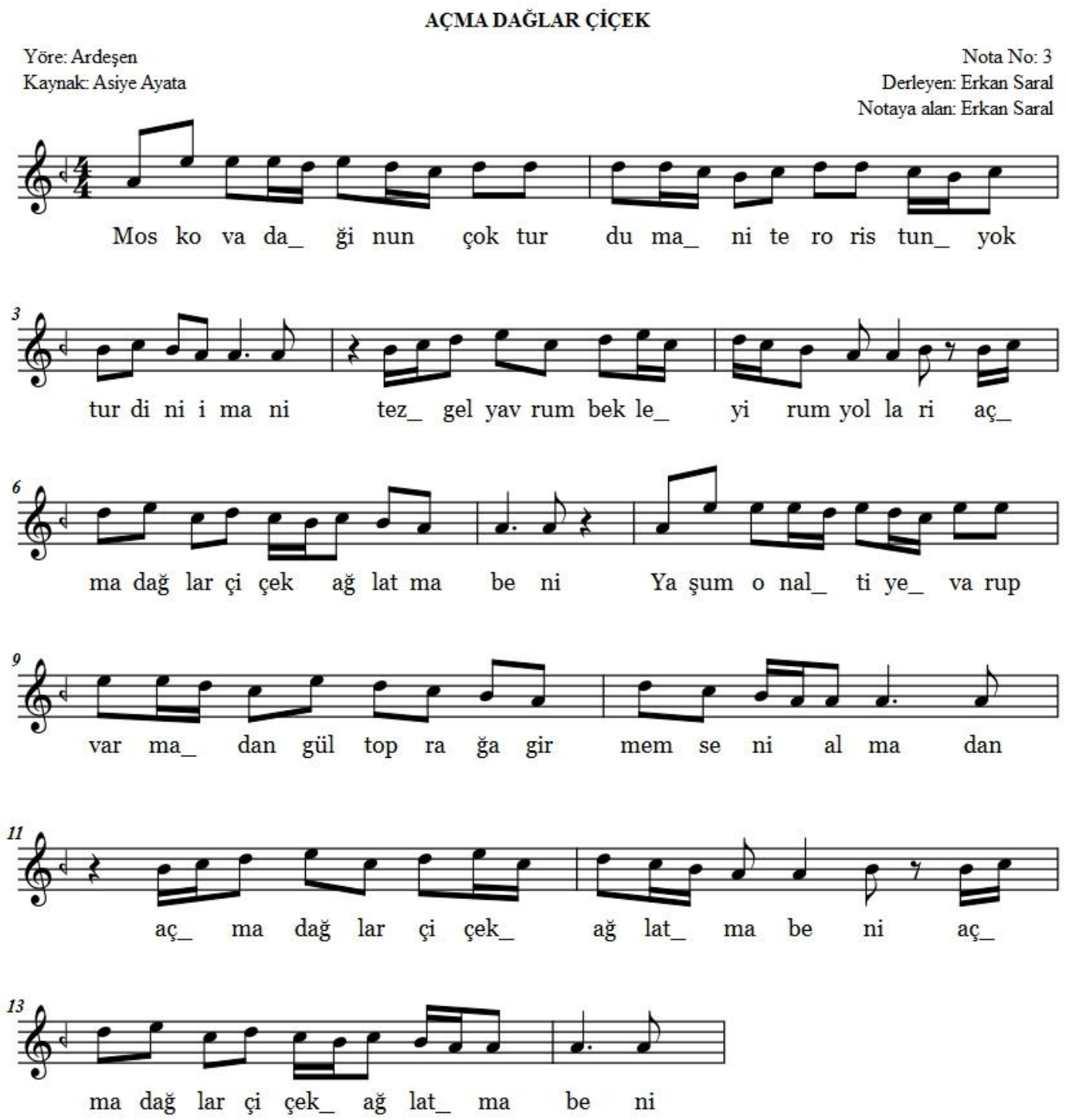

\section{Sonuç}

Destanların geleneksel bir ezgi kalıbının bulunduğu, bu ezgi kalıbının küçük değişikliklerle farklı okuyucularca yorumlanabildiği görülmüştür. Çalışmada bu ezgi kalıbı ile söylenen yedi destan metnine yer verilmiştir. Buna ek olarak farklı destan kaidelerine de (çok nadir) rastlanmıştır. Ritmik yapıları her ne kadar dört dörtlük ölçüye uyum sağlasa da birçok destan serbest ritimli olarak icra edilmektedir. Çalışmada yer verilen destan ezgilerinin, Arel sistemine göre Türk müziği nazariyatında 
Uşşak, Hüseyni ve Kürdi makamlarına tekabül ettiği tespit edilmiştir. Ancak yöre halkı bu makamları kaide olarak zikretmekte, ayrıca kaideleri birbirinden ayıran bir adlandırmaya da başvurmamaktadır. Daha ziyade; geleneksel müzik formlarını birbirinden ayırmada bu farklılıktan bahsedilmektedir. $\mathrm{Bu}$ destan kaidelerinin üzerine farklı olayların bir sonucu olarak yazılan, on birli hece ölçülü şiirlerin çoğunlukla eklendiği de görülmüştür. Yapılan bu düzenlemelere göre işlenen konular genellikle aşk, acı, ölüm, gurbet, hasret ve ayrılık olarak öne çıkmıştır. Karakteristik destan kaidesinin fark edilen vokal özellikleri arasında, iki ve dördüncü mısralarda icra edilen onuncu hecenin uzatılması bulunmaktadır. Geleneksel Ardeşen destanlarında kafiye düzeni aaab şeklindedir. Bu düzende, çoğunlukla altıncı hecede durak bulunmaktadır. Destanların bölgedeki yöresel ifadesi "Destani” şeklindedir.

\section{KAYNAKÇA}

Aksoylu K. (2010). Laz Kültürü Tarih, Dil, Geleneksel ve Toplumsal Yapı. (İkinci Baskı). Ankara: Phoenix Yayınevi.

Alptekin, Gökhan. (2018). Kişisel Görüşme, Ardeşen.

Ayata, Orhan. (2018). Kişisel Görüşme, Ardeşen.

Gedikoğlu H. (2008). Doğu Karadeniz Masallar Öyküler Söylenceler Destanlar (Birinci Bask1). Trabzon: Serender Yayinları.

Karahasanoğlu, S. ve Yavuz E. D. (2013). Müzikte Araştırma Teknikleri, İstanbul Teknik Üniversitesi Yayınları, İstanbul.

Karasar, N. (2015). Bilimsel Araştırma Yöntemi, Nobel Yayın Dağıtım, Ankara.

Oğuz, M. Ö. (Editör). (2004). Türk Halk Edebiyatı El Kitabı. Grafiker Yayınları, Ankara.

Özdemir, M. Nitel Veri Analizi: Sosal Bilimlerde Yöntembilim Sorunsalı Üzerine Bir Çalışma. Eskişehir Osmangazi Üniversitesi Sosyal Bilimler Dergisi. (11/1).

Serin, Süleyman. (2018). Kişisel Görüşme, Ardeşen.

Şişmanlar, Ali İhsan. (2018). Kişisel Görüşme, Ardeşen.

Tekin, Osman Zeki. (2018). Kişisel Görüşme, Ardeşen.

Türk Dil Kurumu, (1998). Türkçe Sözlük, (9. Baskı). TDK Yayınları, Ankara

Yakıc1, A., Doğan, M., Yücel, M., Yelok, S. (2010). Türk Dili ve Kompozisyon Bilgileri. Ankara: Gazi Kitabevi.

Yıldırım, A. ve Şimşek, H. (2003). Sosyal Bilimlerde Bilimlerde Nitel Araştırma Yöntemleri. Ankara: Seçkin Yayınları. 